\title{
LA OMISIÓN DE MADRID EN EL QUIJOTE
}

Ciertamente, aceptar el análisis literario de un tema como éste implica un reto, bien que no exento de interés, porque, como es sabido, la verdad es que Madrid apenas si aparece en la inmortal novela cervantina, y cuando lo hace, no es otra cosa que una mera referencia sin importancia, tangencial, en alguna medida prescindible ${ }^{1}$.

Si espigamos someramente el texto, nos encontramos con alusiones a la capital del reino del siguiente tenor:

- ¿Hay más sino mandar Su Majestad por público pregón que se junten en la corte para un día señalado todos los caballeros andantes que vagan por España, que aunque no viniesen sino media docena, tal podría venir entre ellos que solo bastase a destruir toda la potestad del turco?: (II, 1, p. 582) ${ }^{2}$

- *...dos bravos leones enjaulados, que el general de Orán envía a la corte, presentados a su Majestad...» (II, 17, p. 699)

- «...don Antonio Moreno, a imitación de otra cabeza que vio en Madrid, fabricada por un estampero, hizo ésta en su casa...» (II, 62,p. 1062).

En fin, no creo que merezca la pena seguir por este camino, dado que todas las referencias son de esta índole. Y, claro es, no parece que Madrid tenga ninguna importancia en El Quijote, al menos a juzgar por ellas.

1 Esta frase inicial se debe a que el título original del trabajo era «Madrid y el Quijote», y no el actual, posterior a la finalización del mismo. De ahí que pueda resultar chocante. Pido excusas por ello, pero he preferido modificar el título para clarificar el contenido real del artículo.

2 Cito siempre por la ed. de Martín de Riquer. Barcelona, Ed. Planeta, 1962. 
Si acaso, convendría mencionar la única referencia que tiene un mínimo interés. Me refiero a la que hace doña Rodríguez cuando relata su vida, que pasó por una etapa capitalina, a don Quijote, y le cuenta cómo su marido, escudero de la duquesa, llevándola a las ancas de una mula, «al entrar de la calle de Santiago, en Madrid, que es algo estrechan (II, 48, p. 943), cedió equivocadamente el paso a un alcalde de corte, lo que acarreó el enfado de la duquesa y originó que ella le pinchara, acabando, por eso, los dos en el suelo. Ante lo cual, «alborotóse la Puerta de Guadalajara, digo, la gente baldía que en ella estaba" (ibid.). Esta alusión madrileña, ciertamente, implica un conocimiento muy directo, lógico en un madrileño, de esa zona aledaña de la Plaza Mayor, correspondiente hoy a la de San Miguel, en la que nació Lope de Vega, vivía Juan Pérez de Montalbán, tenía la imprenta su padre y la librería Robles (y el garito), cuya tertulia (así como el otro lugar) frecuentaba Cervantes en sus estancias en la Corte. No es de admirar, pues, la familiaridad que dicha referencia demuestra con este sitio, palpable en la estrecheza de la calle de Santiago o en lo abigarrado del gentío que puebla al decir de la dueña - la famosa Puerta, dado que se trata de una zona asidua para el autor del Quijote. Más resaltable es el hecho de que esta circunstancia se ponga en boca, y pertenezca a la experiencia, de un personaje secundario, y no de nuestro héroe.

Ante esto, poco más se puede decir, aparentemente, de lo que, por ejemplo, dijera Juan Antonio Cabezas: «Don Quijote salió a la madrileña calle de Atocha por la puerta número 85, que correspondía a la imprenta de Juan de la Cuesta. Por tanto, Don Quijote, ese gracioso personaje de papel y tipos móviles (...) nace tipográficamente en Madrid, en esta villa y corte que también pertenece a La Mancha (...) Pero dejemos a los madrileños Don Quijote y Sancho seguir su camino, sus caminos ibéricos y universales, que empezaron en la calle de Atocha...." ${ }^{3}$.

Y por esta vía, obvio es decirlo, la relación entre Madrid y $E l$ Quijote no ofrece mayores alicientes, ni expectativas de interés. Pero, ¿qué otra hay? Ya que ésta, bien escasa es.

No obstante, podríamos plantearnos si la ausencia de Madrid en la obra central de don Miguel se debe a la existencia de algún tipo de animadversión hacia la corte. Pero no es así; no hay enemiga alguna, al menos de manera explícita, a juzgar por cómo aparece la ciudad en otras obras de Cervantes. En La Gitanilla, novela ejemplar que inicia su andadura en la corte, se citan sin encono los "campos de Santa Bárbaran, la iglesia de Santa María o la calle de

3 Juan Antonio Cabezas, Cervantes. Del mito al hombre. Madrid, Biblioteca Nueva, 1967, pp. 367-368. 
Toledo. En La ilustre fregona, por poner otro ejemplo, se cita «la plaza de Madrid», o se compara en buenos términos una fuente vallisoletana con otras madrileñas: «salieron a ver la fuente de Argales, famosa por su antiguedad y sus aguas, a despecho del Caño Dorado y de la reverenda Priora, con paz sea dicho de Leganitos y de la extremadísima fuente Castellanax ${ }^{4}$; o se dice que Carriazo «aprendió a jugar a la taba en Madrid» (p. 140) ${ }^{5}$.

Más aún; no sólo no hay hostilidad alguna contra Madrid, sino que, al contrario, existen manifestaciones expresas de cariño hacia la que, en definitiva, era su ciudad, a pesar de que su vida de impenitente viajero le impidiera vivir en ella con asiduidad. El Viaje del Pamaso no nos dejará mentir:

-Adiós, dije a la humilde choza mía; adiós Madrid; adiós tu Prado y fuentes que manan néctar, llueven ambrosía. Adiós conversaciones suficientes a entretener un pecho cuidadoso, y a dos mil desvalidos pretendientes. Adiós, sitio agradable y mentiroso, do fueron dos gigantes abrasados con el rayo de Júpiter fogoso.

Adiós, teatros públicos, honrados por la ignorancia, que ensalzada veo en cien mil disparates recitados. Adiós de San Felipe el gran paseo, donde si baja o sube el turco galgo como en gaceta de Venecia leo. Adiós hambre sotil de algún hidalgo, que por no verme ante tus puertas muerto, hoy de mi patria y de mímismo salgo» (I, vv. 115-132)

El dolor explícito ante la necesidad de abandonar la corte no deja lugar a dudas. El amor que implica, tampoco. No hay, pues, animadversión alguna de Cervantes contra Madrid. ¿Por qué, entonces, no aparece en El Quijote?

Sin embargo, aunque no aparece apenas, no es menos cierto que la capital del reino puede hallarse implicada en la génesis de la inmortal novela, a causa de la polémica entre Cervantes y Lope de Vega que parece subyacer en la creación cervantina.

4 Cito siempre por la ed. de Harry Sieber, Novelas Ejemplares, II. Madrid, Cátedra, 1982, p. 145.

5 Aunque, obviamente, no se refiere al juego inocente de niños que ha pervivido hasta la actualidad, sino a otro mucho más pernicioso y vicioso -como los que le acompanan en la cita- que, en efecto, se conserva todavia en lugares madrilenos como Colmenar Viejo, donde en dos dras sefialados del ano se apuestan fuertes sumas de dinero a la taba. 
Cuando publica la primera parte de El ingenioso hidalgo don Quijote de La Mancha en 1605, Cervantes se burla en el prólogo, sin citarlo, de Lope de Vega, pues ironiza sobre los escritores que anteponen a sus libros sonetos elogiosos «cuyos autores sean duques, marqueses, condes, obispos, damas o poetas celebémimos», aludiendo, probablemente, a La hermosura de Angélica (1602), al frente de la cual hay, entre otras, poesías laudatorias de un príncipe, de un marqués, de dos condes y de dos damas. Asimismo, se ríe de quienes ponen al final de sus libros una lista de autores citados, simulando erudición y doctrina, como había hecho Lope en El Isidro (1599) y en El peregrino en su patria (1604). Y, sobre todo, lanza sus dardos satíricos contra la pedantería extrema del Fénix, porque en la «Exposición de los nombres poéticos y históricos contenidos en este libro» que acompaña a la Arcadia (1598) había incluido como extraña e inusual palabra el río Tajo, diciendo, «río de Lusitania, nace en las sierras de Cuenca, y tuvo entre los antiguos fama de llevar como Pactolo arenas de oro.... ${ }^{6}$. Por eso dice Cervantes:

...«para mostraros hombre erudito en letras humanas y cosmógrafo, haced de modo como en vuestra historia se nombre el río Tajo, y veréisos luego con otra famosa anotación, poniendo: El rlo Tajo fue asi dicho por un rey de las Españas: tiene su nacimiento en tal lugar y muere en el mar Océano, besando los muros de la famosa ciudad de Lisboa, y es opinión que tiene las arenas de oro, etc.».

Aunque Cervantes no citaba a nadie en concreto, Lope se dio por aludido y se sintió claramente ofendido, ya que el todavía desconocido Avellaneda que publicó la segunda parte apócrifa del Quijote en 1614, sin duda amigo del Fénix, arremetió en el prólogo duramente contra Cervantes, y le tildó de amargado, envidioso, viejo, manco... Y todo, en nombre de Lope, pues dice:

«...si bien en los medios diferenciamos, pues él tomo por tales el ofender a mi, y particularmente a quien tan justamente celebran las naciones más extranjeras, y la nuestra debe tanto, por haber entretenido honestísima y fecundamente tantos años los teatros de Espana con estupendas e innumerables comedias, con el rigor del arte que pide el mundo, y con la seguridad y la limpieza que de un ministro del Santo Oficio se debe esperar" ?.

Cervantes, por su parte, y como era previsible, se defendió y contrarreplicó en el prólogo de su Segunda parte del ingenioso ca-

- Cito por la ed. de Joaquín de Entrambasaguas, Obras Completas de Lope de Vega, I. Madrid, CSIC, 1965, p. 171.

7 Cito por la ed. cit. de Martín de Riquer, que incluye el Quijote de Avellaneda, pp. 1147-8. 
ballero don Quijote de La Mancha (1615), con la fina ironía que le caracteriza:

*...no tengo yo de perseguir a ningún sacerdote, y más si tiene por añadidura ser familiar del Santo Oficio; y si él lo dijo por quien parece que lo dijo, engañóse de todo en todo; que del tal adoro el ingenio, admiro las obras, y la ocupación continua y virtuosax.

Y en esta sutil ironía contra Lope sí está presente, y bien presente, Madrid, ya que Cervantes pone en solfa al Fénix, que en efecto era familiar de la Inquisición y acababa de ordenarse sacerdote en 1614 , porque conoce bien sus idas y venidas amorosas, a despecho de su condición clerical, gracias a que es su vecino en la villa y corte, y que vive al lado de él, ya en la calle Francos, esquina a la del León, ya en Huertas. No olvidemos que algunas ventanas de la casa cervantina daban a la calle del León, esto es, al mentidero, en el que sin duda serían moneda corriente las andanzas enoticas de Lope. Sin duda nuestro novelista habría visto a Lope, flamante sacerdote, en compañía de alguna dama, y habría oído hablar sobre el cura galán en el barrio, en su barrio común madrileño. Con todo, no obstante la presencia evidente de la ciudad, seguimos en los aledaños del Quijote, ya que lo expuesto sólo afecta a los prólogos y a la guerra literaria cervantino-lopesca.

Aunque hay, o puede haber, algo más al respecto, dado que los primeros capítulos de la inmortal novela se basan en el modelo del llamado Entremés de los romances anónimo, fechado hacia 1596, como definitivamente demostrara Menéndez Pidal ${ }^{8}$. Dicho entremés es el fundamento de la primera salida de don Quijote, que constituye una novela corta evidente, escrita y concebida sin división en capítulos, ya que Cervantes la segmentó después, cuando se decidió a proseguirla, sin preocuparse además excesivamente por ello, sin hacerlo con demasiada precisión, cortando por donde le pareció. Y ello hasta tal punto, que el cap. III acaba diciendo: «le dejo ir a la buena hora», y el IV comienza expresando: «La del alba sería». Pero más significativo todavia, en este sentido, es el engarce entre el cap. V y el VI, pues Martín de Riquer, con buen criterio, puntúa sólo con una coma la separación entre uno y otro, a causa de que el primero concluye con la siguiente frase: «con el cual se vino a casa de don Quijote,» y el segundo se inicia así: «el cual aún todavía

8 Ramón Mrnéndez Pidal, «Un aspecto en la elaboración del Quijote», en De Cervantes y Lope de Vega. Madrid, Espasa-Calpe, 1940, pp. 9-60. Este trabajo zanj6 la cuestión, anteriormente defendida por algunos cervantistas, de que el Entremés de los romances pudiera no ser la fuente del Cervantes, sino al contrario, la copia de los primeros capitulos quijotescos, demostrando con claridad que era su modelo y fechándolo en 1596. 
dormíax. Si a esto unimos que relata la primera salida y el primer regreso del hidalgo, que el héroe va solo en ella, sin la compañia de Sancho, y que, en consonancia con el hecho de que su locura se debe a la lectura de libros de caballerfas, la novela se cierra, logicamente, con el conocido escrutinio de estas novelas y, probablemente, con la siguiente y sentenciosa frase, perfecto colofón para una probable novela ejemplar: «Aquella noche quemó y abrasó el ama cuantos libros había en el corral, y en toda la casa, y tales debieron de arder que merecían guardarse en perpetuos archivos; mas no lo permitió su suerte y la pereza del escrutiñador, y así, se cumplió el refrán en ellos de que pagan a las veces justos por pecadores» (I, 7, p. 83). Si sumamos todos estos datos, repito, no hay duda de que El Quijote se inición como una novelita corta.

Es más, como una novela que, probablemente, se publicó en 1604, aunque no conservemos ejemplar alguno de esta hipotética impresión. Y es que sí tenemos elementos suficientes como para pensar que sucedió así, ya que en una carta de Lope de Vega fechada en Toledo el 14 de agosto de 1604, dice el Fénix: «De poetas, no digo: buen siglo es éste. Muchos están en cierne para el año que viene, pero ninguno hay $\tan$ malo como Cervantes ni tan necio que alabe a Don Quijote» ${ }^{9}$. Pero no sólo Lope conocía dicho Quijote, sino también Francisco López de Ubeda, el autor de La Pícara Justina, obra publicada aceleradamente, en varias imprentas a la vez, a finales de 1604, para coadyuvar al proceso de ennoblecimiento de Rodrigo Calderón, y en la cual figura como héroe indudablemente literario ya conocido nuestro ingenioso hidalgo, pues la pícara dice:

\author{
Soy la rein- de Picandr-, \\ Más que la Rud- conoci-, \\ Más famo- que doña Oli-, \\ Que don Quijo- y Lazari-, \\ Que Alfarach-y Celesti- ${ }^{10}$.
}

La referencia de la pícara, en efecto, no deja lugar a dudas: don Quijote aparece junto a Lazarillo, Guzmán de Alfarache y Celestina, como personaje literario famoso ya en $1604^{\prime \prime}$, lo que alude a un impreso ya existente por esa fechas. Edición perdida que, en

- Cito por la ed. de Nicolás Marín, Lope de Vega, Cartas. Madrid, Castalia, 1985, p. 68.

10 Cito por mi ed. de La Plcara Justina. Madrid, Editora Nacional, 1977, vol. II, p. 611 .

ii Para todo lo referente a las relaciones entre Cervantes y Francisco López de Ubeda, véase el excelente trabajo de Marcel BAtallon, como todos los suyos, - Urcanda entre Don Quijote y La Plcara Justinas, en Picaros y picaresca. Madrid, Taurus, 1969, pp. 53-90. 
efecto, corroboró el descubrimiento que hizo Oliver Asín ${ }^{12}$ del documento del «morisco Juan Pérez o Ibrahim Taibilí, donde se relata un episodio acaecido el 24 de agosto de 1604 en la feria de Alcalá de Henares, en el que se alude al Quijote como a un libro ya impreso. Todo esto explicaría perfectamente la razón de que en el privilegio y en la tasa del Quijote de 1065, fechados en septiembre y diciembre de 1064, se repita tres veces un título diferente, no El ingenioso hidalgo don Quijote de La Mancha, sino El ingenioso hidalgo de La Mancha, posible título de la más que probable novela corta editada en 1604.

En todo caso, lo que interesa a nuestro propósito acerca de esto relaciona de nuevo a Lope y a Cervantes. Me refiero a la vieja hipótesis de Millé ${ }^{13}$, según la cual el Entremés de los romances bien pudo ser una sátira contra Lope de Vega, dado que su protagonista, Bartolo, loco por leer romances, se cree un héroe del Romancero, $y$, recién casado, abandona a su mujer y se empeña en ir a luchar contra el Draque, contra Inglaterra, al igual que Lope, en cierta manera «loco» por los romances, a través de los cuales nos relató su biografía amorosa, incluso con escándalo y proceso por libelos anejo, recién casado con Isabel de Urbina, abandona a su mujer y se embarca en la Armada que fue contra Inglaterra, en La Invencible. Si esto es asi, y dado que el citado entremés es el modelo fundamental de la novela corta probablemente impresa en 1604 con el título de El ingenioso hidalgo de La Mancha, o de los primeros capítulos del Quijote que conocemos, si se quiere, la novela, en cualquier caso, sería una burla de Lope, una barroca alusión a una alusión dirigida contra el creador de la comedia nueva, con lo cual, en la génesis de la inmortal novela se hallaría la pugna entre los dos madrileños, se hallaría Madrid en el centro, aunque sólo fuera indirectamente, a través de las andanzas capitalinas del joven Lope. No debe olvidarse que también Cervantes era un consumado autor de romances, a juzgar por la declaración que hace un testigo, precisamente en el proceso por libelos seguido contra Lope de Vega por sus ataques poéticos a Elena Osorio y su familia. Dicho testigo asegura que, a propósito de un romance satírico, Luis de Vargas Manrique habia sentenciado: «Este romance es del estilo de cuatro o cinco que solos los podrán hacer: que podrá ser de Linán, y no está aquí, y de Cervantes, y no está aquí; pues mío no es, puede ser de Vivar o de Lope de Vega" ${ }^{14}$.

Seguimos, con todo, en los alrededores del problema, pues de hecho lo expuesto sólo afecta a la novela corta primigenia, de más

12 JAIME OLIVER ASIN, «El Quijote de 1604», BRAE, XXVII, 1948, pp. 90-126.

13 Juan Minlé y Gumanez, Sobre la génesis del «Quijote». Barcelona, 1930.

14 Cit. por A. Bonmu, Cervantes y su obra. Madrid, 1916, p. 169. 
un miembro perfecto de la sociedad conformista del Barroco español ${ }^{16}$.

Pero el de Cervantes no es así, como es bien sabido, sino todo lo contrario, la obra de uno de los últimos humanistas españoles, defensor de los valores individuales del ser humano y, por tanto, opuesta a los principios ideológicos supranacionales del siglo XVI. Por ello, y por verosimilitud, don Quijote necesita el campo, el espacio abierto, los caminos desembarazados, los pueblos distanciados, donde, como acaece en el texto cervantino, pueda incluso dejar en libertad a unos delincuentes justamente condenados a las galeras, sin verse forzosamente obligado a dar con sus huesos en presidio, un marco narrativo donde, por ejemplo, sea verosímil su huida hacia Sierra Morena para ocultarse a la justicia, para escapar de la Santa Hermandad. En una ciudad como Madrid, en cambio, pronto hubiera sido apresado por los alguaciles y metido entre rejas.

Sin embargo, no se trata sólo de una cuestión de verosimilitud novelesca, sino también de necesidad expresiva total; se trata de dar cauce apropiado a la misión del héroe: es necesario posibilitar literariamente el sueño de la edad de oro, el mito de un mundo sin tuyo ni mío, sin jueces ni justicia: el ámbito solitario de los campos inmensos, de los espacios despoblados, más próximo, obviamente, a la utopía del siglo dorado que las aglomeraciones urbanas; pero dentro de los «caminos reales», claro está, para que sea realista el encuentro caballeresco con los desfavorecidos, los débiles y los menesterosos. Don Quijote precisa, en suma, de la libertad de acción que únicamente la naturaleza ajena a la civilización puede ofrecer. De otro modo, su vida no tendría sentido.

La cuestión de Madrid y El Quijote, por tanto, no debe plantearse mediante el rastreo infructuoso de las exiguas e intrascendentes alusiones capitalinas que hay en el texto de la inmortal novela, sino, a la inversa, mediante la búsqueda e indagación de las causas por las que se excluye la Corte de las andanzas quijotescas. ¿Por qué no aparece Madrid? Esa es la pregunta.

No es por animadversión hacia su ciudad, desde luego, dado que Cervantes era madrileño, en mayor o menor medida, y dado que la capital de las Españas aparece positivamente conceptuada por él en otros textos suyos, como ya hemos visto. ¿Es por necesidad verosimilizadora, como acabamos de exponer? Sí, pero no totalmente; sí, pero sólo en parte; ya que, de hecho, la novela culmina en otra ciudad grande, en Barcelona. La pregunta, entonces, es obvia: ¿Y por qué en Barcelona, y no en Madrid?

16 Stephen Grman, Cervantes y Avellaneda. Estudio de una imitación. México, Fondo de Cultura Económica, 1951. 
Como es sabido, Cervantes pensaba llevar a sus héroes a Zaragoza, pero al hacerlo antes Avellaneda en el apócrifo, modificó el trazado de su viaje y los condujo a Bancelona. Bien es cierto que, en principio, nada positivo parece deducirse de ello, antes al contrario, dado que la ciudad condal es el lugar donde nuestro héroe es definitivamente vencido, donde es derrotado ya para siempre, tanto física como moral y aun metafísicamente, por Sansón Carasco, el caballero de la Blanca Luna. En consecuencia, desde la perspectiva interna en la novela, podriamos pensar que Barcelona cumple una función harto negativa en el desarrollo de la obra, ya que preside el final de los sueños utópicos y la conclusión de las andanzas caballerescas de don Quijote. Pero no es así, muy significativamente, porque a pesar de todo ello, la valoración que el texto ofrece de la capital catalana es absolutamente positiva y elogiosa, aun después de la derrota. Las palabras de don Quijote no dejan lugar a dudas; oigámoslas:

Barcelona, anchivo de la cortesía, albergue de los extranjeros, hospital de los pobres, patria de los valientes, venganza de los ofendidos y correspondencia grata de firmes amistades, y en sitio y en belleza, única. Y aunque los sucesos que en ella me han sucedido no son de mucho gusto, sino de mucha pesadumbre, los llevo sin ella, solo por haberla visto (II, 72).

La alabanza de Barcelona es total, sin paliativos, exageradamente llamativa además por el hecho de aparecer después de la derrota en ella acaecida, justo cuando el héroe regresa a su aldea definitivamente vencido, esto es, cuando ya ha perdido para siempre su condición de caballero andante, o lo que es lo mismo, cuando se ha derrumbado todo lo que daba sentido a su existencia. En ese preciso momento en que el dolor es más intenso, don Quijote dice que su «pesadumbrex absoluta desaparece sollo por haber visto la ciudad. No puede haber elogio más rotundo y claro, pues la ciudad y su belleza se sobreponen como un bálsamo milagroso incluso a la catástrofe final de la novela. Por encima de la herida postrera, tras la frustración última del sueño utópico, se yergue la imagen viva y reconfortadora de Barcelona. ¿A qué se debe tan desmedida alabanza? ¿Por qué concluye en la capital catalana el viaje del heroe? ¿Por qué lo hace, además, rodeado del morisco Ricote, su hija Ana Félix, Antonio Moreno, etc., y precedido por el bandolero Roque Guinart? ¿Que implica todo esto? Y, sobre todo, ¿hay algun nexo entre la ausencia de Madrid y la presencia casi gloriosa de Bancelona? ¿Por qué aparece, pujante y ensalzada, la una, mientras desaparece la otra urbe? Indudablemente, la omisión sistemática de la Corte se relaciona con la brillante presencia de la capital catalana 
en la inmortal novela. No cabe duda de eso. Por ello, las motivaciones de tan peculiar presencia/ausencia serán el objeto central de nuestro trabajo a partir de este momento.

Ya desde la aparición de Roque Guinart en el camino quijotesco, nos damos cuenta de su extraordinaria importancia, $y$, de inmediato, percibimos que dicho personaje se halla ligado a la positiva visión de Barcelona que ofrece el texto, puesto que es él quien acompaña a don Quijote hasta la ciudad y le deja en las manos de su amigo Antonio Moreno.

Roque Guinart es prototipo de bandoleros generosos ${ }^{17}$, caballero valiente, y justiciero, de noble origen y de talante más compasivo que riguroso, a pesar de su condición de bandido, capitán equitativo que distribuye el botín con ecuanimidad e incluso restituye lo robado si es de justicia, denominado, por eso, «cortés», «liberal», e incluso «el gran Roque», y, a causa de tan insólitas virtudes, muy admirado por todos... No es raro que tan extraordinario personaje deje pasmado a nuestro héroe. No es raro que don Quijote quede empequeñecido ante tan singular salteador. Como dice Riquer: «En todo el episodio el lector advierte, con cierta pena y con desilusión, que don Quijote se eclipsa, se apaga y se transforma en un mero espectador» ${ }^{18}$. Este suceso, ya de por sí poco habitual, aumenta su extrañeza cuando nos damos cuenta de que nos encontramos ante un ser real, de carne y hueso, ante Perot Rocaguinarda, aristócrata catalán que se había hecho bandolero y que por las fechas del segundo Quijote, ya perdonado y rehabilitado, era Capitán de Galeras en Náples.

De este modo, la realidad auténtica pasa a formar parte de la novela, que magnifica a un personaje histórico y lo sitúa a la altura del propio héroe de ficción, del propio don Quijote, el cual (hecho sin parangón en la novela), por primera y única vez, propone al bandolero catalán que le acompañe, que se haga, como él, caballero andante:

Y si vuestra merced quiere ahorrar camino y ponerse con facilidad en el de su salvación, véngase conmigo, que yo le enseñaré a ser caballero andante (II, 60, p. 1047).

Jamás don Quijote haría eso; jamás lo hace, excepto en esta ocasión, porque la caballería andante, como sabemos, es para él la

17 Tema, éste, que aparece, como es sabido, en otros relatos cervantinos y en los de sus contemporáneos. Me he ocupado de estas cuestiones, en «El bandolero en la novela del Siglo de Oro», en El bandolero y su imagen en el Siglo de Oro. Madrid, Univ. Autónoma de Madrid, 1989, pp. 201-215.

18 MURTIN DE RIOUER, Aproximación al Quijote. Barcelona, Salvat, 1970, p. 130. 
más preciada y sublime misión que puede deparar el mundo. Y sin embargo ofrece el sueño utópico que da sentido a su vida a otro personaje, a un hombre real. ¿Por qué? Porque le considera semejante a él mismo, equiparable a su mundo literario, y admirable por su capacidad de rebelde sin par. Porque como a él le persigue la justicia de la Santa Hermandad, acosa a Roque el virrey de Barcelona, y a causa de ello, al igual que nuestro héroe, el bandolero caballeresco vive en el campo, lejos de la ciudad, para poder mantener su querida libertad por encima de todo, aunque para eso, igualmente, tenga que rechazar la autoridad legal y no acepte otra ley que la de sus propios fueros, como hace don Quijote. La admiración que siente el hidalgo manchego por Roque Guinart es, pues, totalmente lógica, sobre todo si pensamos que el catalán no está loco y, además, es un ser de carne y hueso.

Todo ello hace del bandido generoso un personaje singular y le convierte en un verdadero modelo de comportamiento quijotescto. Pues bien, $\tan$ excepcional hombre es quien introduce a don Quijote en Barcelona. Así pues, la presentación de la ciudad no puede ser más significativa. Es el símbolo de rebeldía de la ciudad rebelde contra la autoridad todopoderosa que emana de la Corte opresora; o, simplemente, el rebelde de la ciudad reblede. Por eso no aparece Madrid, porque es la Corte; y sí elogiosamente alabada, Barcelona.

Y es que no se trata sólo de la relación entre la ciudad y el bandolero romántico, sino que también se reúnen en ella, harto significativamente, el morisco Ricote y su hija Ana Félix. Y Ricote, no lo olvidemos, es otro defensor de la libertad, como Roque Guinart y don Quijote, pues de su boca salen las siguientes palabras:

...Y llegué a Alemania, y allı me pareció que se podía vivir con más libertad, porque sus habitadores (...) cada uno vive como quiere, porque en la mayor parte della se vive con libertad de conciencia (II, 54, p. 995).

Hay más: el morisco, como es sabido, había sido expulsado de España, al igual que todos los de su raza, entre 1609 y 1614. Es, por tanto, un marginado de la sociedad (como lo son, de otra manera, Roque y nuestro hidalgo), es un ser discriminado por el poder y desgajado de su patria contra toda justicia e innecesariamente, puesto que ama a España por encima de todo ${ }^{19}$. Leamos sus reveladoras palabras:

Doquiera que estamos lloramos por Espana; que, en fin, nacimos en ella $y$ es nuestra patria natural; en ninguna parte hallamos el acogimiento que

19 Vid. Francisco Marouez Vinunueva, «El morisco Ricote o la hispana razón de estadox, en Personajes y temas del Quijote. Madrid, Taurus, 1975, pp. 229-335. 
nuestro desventura desea; y en Berberia, y en todas las partes de Africa donde esperabamos ser recibidos, acogidos y regalados, alli es donde más nos ofenden y maltratan (...) y es el deseo tan erande que casi todos tenemos de volver a Espana, que los más de aquellos (y son muchos) que saben la lengua como yo, se vuelven a ella, y dejan allá sus mujeres y sus hijos desamparados: tanto es el amor que la tienen; y agora conozco y experimento lo que suele decirse: que es dulce el amor de la patria.

Pues bien, Ricote no sólo se halla en Barcelona, sino que se encuentra allí a su hija Ana Félix, recién liberada de los piratas, con lo que al reencuentro con su patria se une el hallazgo de su hija, a la que no había visto desde la expulsión; pero la felicidad no acaba ahi, porque desde la ciudad condal parte una flotilla que libera a don Gregorio, el enamorado de Ana Félix, y lo trae a Barcelona. Y, para que nada falte a tan dichoso lugar, el propio virrey y, sobre todo, Antonio Moreno se proponen negociar en la Corte para que el morisco y su familia no tengan que abandonar el pais:

De alli a dos dias trató el visorrey con don Antonio qué modo tendrian para que Ana Félix y su padre quedasen en Espana, pareciéndoles no ser de inconveniente alguno que quedasen en ella hija tan cristiana y padre, al parecer, tan bien intencionado. Don Antonio se ofreció venir a la Corte a negociarlo, donde habla de venir forzosamente a otros negocios, dando a entender que en ella, por medio del favor y de las dádivas, muchas coses dificultosas se acaban (II, 65).

En Barccelona, pues, se solucionan algunos problemas de la familia Ricote, y de alls parte el deseo de llevar a feliz término los otros. Por aquellas fechas, Roque Guinart ya estaba perdonado y rehabilitado en la realidad histórica. Quizá Cervantes juege con dicha situación real. Don Quijote, por su parte, encuentra alli, merced a su derrota, la única manera de regresar a su casa y de recuperar su cordura pendida; y aunque esto es más triste que dichoso, desde la perspectiva de la utopía idealizada, es la mejor solución, desde la optica de la realidad cotidiana. Y es que la presencia rotundamente alabada de la ciudad condal en la novela, resulta tambien positiva para los personajes all reunidos, y en ello, en su carácter de lugar donde se solucionan los problemas (xalbergue de estranjeros» - decía don Quijote-), tiene una relación directa con la situación real de la Espana áurea; o mejor aún, con la crítica de dicha situación. Por eso, y no es casualidad, se reúnen alli moriscos, bandoleros $y$, por supuesto, catalanes, junto a nuestro caballero. Todos ellos seres marginados, discriminados, perseguidos. Todos ellos, pues, acosados por un poder absoluto que impide la libertad; por un poder nacional o supranacional que no permite la libertad individual; por un poder que emana de la Corte, y la Corte es 
Madrid. De ahí la omisión de ésta ciudad en las páginas de la novela; de ahí la presencia de Barcelona, en claro contraste.

La ausencia de Madrid, es decir, de la Corte, explica la inclusión de Barcelona, prototipo de ciudad rebelde donde coinciden los rebeldes, los que no aceptan la autoridad absoluta que procede de Madrid y donde encuentran solución sus problemas. Nada más coherente con el mundo quijotesco, o lo que es lo mismo, con la defensa apasionada de la libertad:

La libertad, Sancho - dice don Quijote-, es uno de los más preciosos dones que a los hombres dieron los cielos; con ella no pueden igualarse los tesoros que encierra la tierra ni el mar encubre; por la libertad, así como por la honra, se puede y debe aventurar la vida, y, por el contrario, el cautiverio es el mayor mal que puede venir a los hombres (II, 58).

Porque la libertad es el eje ideológico de la novela cervantina, y no sólo por lo que el héroe dice, sino por lo que hace, o porque hace lo que dice, tanto cuando libera a los galeotes y pone en tela de juicio la capacidad del Rey para forzar a los delincuentes, como cuando defiende la libertad amorosa de Marcela contra las pretensiones de los amigos de Grisóstomo, etc. Más aún, la libertad es una de las claves de la poética novelesca cervantina, como he demostrado en otro lugar ${ }^{20}$, presente en los personajes, en el autor y en los lectores, evidente en la visión del mundo y en la concepción de la sociedad, manifiesta en la teoría y en la práctica literarias; siempre abierta, tolerante y flexible con las peculiaridades individuales, nunca cerrada excepto, quizá, en eso mismo, en la defensa a ultranza de la libertad.

Una concepción semejante, obvio es decirlo, choca frontalmente con el centro del poder opresivo, con la sede de la negación de la libertad, esto es, con la Corte de la monarquía absoluta de los Austrias, con Madrid. Por eso no aparece la ciudad en las páginas de la novela.

Pero no sólo por eso, sino también porque don Quijote es un personaje plenamente consciente de su militancia, que sabe la profesión caballeresca que ejerce y conoce la existencia de otro tipo de caballeros diferentes. Por ello defiende sin paliativos la superioridad de la caballería andante sobre la caballería cortesana, lo cual, entre otras cosas, implica abogar por la vida en el campo abierto y libre, donde el caballero no conoce otra ley que la de sus propios fueros, y rechazar, por tanto, la vida en la Corte, siempre coartada

20 Antonio Rey huzas, «Cervantes, el Quijote, y la poética de la libertad», en Actas de I Coloquio de la Asociación Internacional de Cervantistas. Barcelona, Anthropos, 1990, pp. 369-380. Vid., además, LuIs Rosales, Cervantes y la libertad. Madrid, Graficas Valera, 1959-60. 
y limitada por las más diversas imposiciones y convenciones externas a la independencia del ser humano. Así se lo dice a don Diego Miranda:

Bien parece un gallando caballero, a los ojos de su rey, en mitad de una gran plaza, dar una lanzada con felice suceso a un bravo toro (...), bien parecen todos aquellos caballeros que en ejercicios militares, o que lo parezcan, entretienen y alegran, y, si se puede decir, honran las cortes de sus principes; pero sobre todos estos parece mejor un caballero andante, que por los desiertos, por las soledades, por las encrucijadas, por las selvas y por los montes anda buscando peligrosas aventuras, con intención de darles dichosa y bien afortunada cima, sólo por alcanzar gloriosa fama y duradera. Mejor parece, digo, un caballero andante socorriendo a una viuda en algún despoblado que un cortesano caballero requebrando a una doncella en las ciudades... (II, 17).

Nuestro héroe es consciente de su misión reformadora de la sociedad, $y$, como es bien sabido, desea sustituir la kedad de hierrox en que le ha tocado vivir, por la «edad de orox, por el viejo mito clásico en el que reinan la libertad y la prosperidad, sin propiedad privada (sin tuyo ni mio), ni autoridad opresiva, ni jueces ni justicia, ni posibilidad de imponer la voluntad de uno sobre la de otro, etc... A tal fin, evidentemente, necesita rechazar las ciudades (y así lo hace: Barcelona es la excepción que confirma la regla) y, sobre todo, la Corte, el centro de la autoridad y de la justicia legal, todopoderosa y uniformadora. De ahí la elusión de Madrid, a causa de su identificación con la Corte, pero no como ciudad, como su ciudad (la de Cervantes), a la que el autor expresó en ocasiones su cariño, como veramos al inicio de este trabajo.

El menosprecio de corte, por cierto, no es patrimonio exclusivo del Quijote, sino que aparece en otros textos cervantinos, como Los trabajos de Persiles y Sigismunda, por ejemplo, donde Periandro y Auristela «tampoco quisieron pasar por Madrid, donde a la sazón estaba la corte, temiendo algún estorbo que su camino les impidiesex (III, 8). Y ello se debe a la misma actitud quijotesca de rechazo y desconfianza. Actitud anticortesana directamente heredada del humanismo quinientista, de los Luis Vives, Fray Antonio de Guevara, Torquemada, Fray Luis de León, etc., que constituyen el basamento ideológico de Cervantes, quizá, junto con Pedro de Valencia, el discípulo de Arias Montano, uno de los últimos humanistas de la España del Siglo de Oro. Y como tal humanista, don Miguel erigió a su hidalgo manchego, más que a ningún otro de sus entes de ficción, en defensor de la libertad individual, del perspectivismo, 0 si se quiere, de las «opiniones» frente a la «OPINIÓN* (por decirlo en términos de Américo Castro), lo que presuponía abogar por la aldea frente a la corte y por el campo frente a la ciudad. 
En consecuencia, la omisión de Madrid en las páginas del Quijote se debe, exclusivamente, a su calidad de Corte de las Españas, y nada más. Sin que haya ningún tipo de animadversión hacia la que, en definitiva, era su ciudad. Ciudad por cuyas calles paseó, pensó y sintió el gran novelista, a quien ha evocado así, madrileñamente, con hermosas e inteligentes palabras, Pedro, el protagonista de Tiempo de Silencio, la gran novela de Luis Martín Santos, cuando recorre las mismas calles de Huertas, Lope de Vega, Cervantes, etc., las mismas calles de evocación cervantina:

Por allí había vivido Cervantes - ¿o fue Lope?- o más bien los dos. Si; por alli, por aquellas calles que habían conservado tan limpiamente su aspecto provinciano, como un quiste dentro de la gran ciudad. Cervantes, Cervantes. ¿Puede realmente haber existido en semejante pueblo, en tal ciudad como ésta, en tales calles insignificantes y vulgares un hombre que tuviera esa visión de lo humano, esa creencia en la libertad, esa melancolía desengañada tan lejana de todo heroísmo como de toda exageración, de todo fanatismo como de toda certeza? ¿Puede haber respirado este aire tan excesivamente limpio y haber sido consciente como su obra indica de la naturaleza de la sociedad en la que se veŕa obligado a cobrar impuestos, matar turcos, perder manos, solicitar favores, poblar cárceles y escribir un libro que únicamente había de hacer reír? (...) ¿Qué es lo que ha querido decirnos el hombre que más sabía del hombre de su tiempo? ¿Qué significa que quien sabra que la locura no es sino la nada, el hueco, lo vacío, afirmara que solamente en la locura reposa el ser-moral del hombre?

\author{
ANTONIO Rey Hazas \\ Universidad Autónoma de Madrid
}

